\title{
Strengthening of masonry vaults with transversal diaphragms: a numerical approach
}

\author{
Department of Civil Engineering, ISISE, \\ University of Minho, \\ Campus de Azurém, \\ Guimarães 4800-058, Portugal \\ Email: j.ptaszkowska@gmail.com \\ Email: danvco@civil.uminho.pt \\ *Corresponding author
}

Joanna Ptaszkowska and Daniel V. Oliveira*

\begin{abstract}
The compatible strengthening of historical constructions is a critical issue in modern restoration practice. Among others, numerical modelling became a powerful instrument in the practice of checking the suitability and effectiveness of a given structural strengthening solution. In particular, the topic of numerical modelling of masonry arches and vaults was developed by many researchers for several years. This paper is focused on the numerical representation of a traditional strengthening technique, based on the use of transversal masonry diaphragms applied to arches and vaults. Macro and micromodelling approaches were considered in this work as to discuss the adequacy and efficiency of the strengthened method and also compare results between the two approaches. To further define the properties and effectiveness of the strengthening solution, a parametric study was conducted by means of geometrical and mechanical modifications applied to the diaphragms.
\end{abstract}

Keywords: masonry vault; numerical modelling; strengthening; transversal diaphragm.

Reference to this paper should be made as follows: Ptaszkowska, J. and Oliveira, D.V. (2017) 'Strengthening of masonry vaults with transversal diaphragms: a numerical approach', Int. J. Masonry Research and Innovation, Vol. 2, Nos. 2/3, pp.241-257.

Biographical notes: Joanna Ptaszkowska completed MSc in Civil Engineering at Wroclaw University of Technology, Poland, and completed the SAHC Master Course in 2013, at Technical University of Catalonia, Spain, and University of Minho, Portugal. She is currently working in a Structural Design Company in Poland. Her main field of work deals with reinforced concrete constructions and steel halls. Additionally, she is also involved in the execution of renovation projects of historical buildings.

Daniel V. Oliveira is an Associate Professor at University of Minho, Portugal. His main research interests are related to earthquake engineering, strengthening of masonry based on traditional and innovative composite materials, earthen construction, masonry arch bridges and risk management. He has been involved in several European and national research projects in the field of masonry constructions, and supervisor of $17 \mathrm{PhD}$ students and more than $50 \mathrm{MSc}$ students. He is an Author of more than 50 ISI papers, holding an h-index currently of 15 . He is a Deputy Coordinator of the Erasmus Mundus Masters' Course in Structural Analysis of Monuments and Historical Constructions (SAHC) since 2007. 
This paper is a revised and expanded version of a paper entitled 'Numerical modeling of masonry vaults strengthened with transversal diaphragms', presented at the 9th International Conference on Structural Analysis of Historical Constructions, October, 2014, Mexico.

\section{Introduction}

Amongst the different structural elements of historical constructions, masonry arches and vaults deserve a special attention. These structural components allowed the construction of some of the most beautiful and spectacular buildings (e.g. gothic cathedrals) during the past centuries. The use of vault-like structures allowed constructions of great scale to emerge, using materials of low or almost null tensile strength, as the case of masonry (Heyman, 1982; Ochsendorf, 2002).

Many historical buildings, including those classified as cultural heritage, are in poor condition, or even in a condition characterised as endangered by severe damage or even collapse. Therefore, it is crucial to find ways that might guarantee life elongation of the most critical structural components. In the particular case of historical buildings, the matter becomes even more complicated, since they usually cannot be altered in a way that might compromise its original conception and meaning. Consequently, responsible strengthening of historical constructions is becoming an important issue in modern restoration practice (Carocci, 2001; Ministero per i beni e le attività culturali, 2010).

Over decades, many preservation works have been done and a significant number of strengthening techniques were developed. Unfortunately, not all of them were successful, as sometimes interventions destroyed the cultural value of constructions. To prevent repetition of poor restoration practices, the International Council on Monuments and Sites (ICOMOS) formulated some ground guidelines to organise the work to be done in historical constructions, so that monuments would be approached in a suitable way. International Scientific Committee for Analysis and Restoration of Structures of Architectural Heritage (ISCARSAH) created a set of principles and recommendations aimed at ensuring rational methods of analysis and repair of historical constructions appropriate to the cultural context (ICOMOS/ISCARSAH Committee, 2003). Here, it is recognised that conventional calculation techniques and legal codes or standards oriented to the design of modern constructions may be difficult to apply, or even inapplicable, to historical structures. Additionally, ISCARSAH recommendations state the importance of a scientific, multidisciplinary approach involving historical investigation, inspection, monitoring and structural modelling and analysis.

During decades of rehabilitation of historical constructions, many strengthening techniques were developed. With the progress of technology, more sophisticated approaches were created, therefore nowadays there is a wide range of intervention techniques that can be used. Choosing the right method is a complicated process in which many factors have to be taken into consideration, such as: cultural value of the structure, source of damage, reversibility of the technique and its interference with the original element, cost estimation, feasibility and efficiency of the method in particular conditions.

This paper is focused on the numerical modelling of strengthened masonry vaults. This topic has been approached by many researchers, but has been typically concentrated 
on the use of innovative materials like Fiber Reinforced Polymer (FRP) (Valluzzi et al., 2001; Oliveira et al., 2010) and, more recently, Steel Reinforced Polymer (SRP) or Textile Reinforced Mortar (TRM) (Garmendia et al., 2011). The use of modern materials is a reasonable approach as many constructions require significant increase of loadbearing capacity that can only be provided by the use of the previously mentioned techniques. With the increasing use of modern composite materials, many traditional reinforcement materials and methods were disregarded and considered as not efficient enough in comparison with the new ones. However, there is a significant trend towards the use of traditional strengthening techniques due to their traditional compatible behaviour with the masonry substrate.

In particular, this paper presents and discusses the numerical modelling of a type of traditional strengthening technique, namely the use of extrados stiffening elements made of masonry (also called masonry ribs). This method, which has some significant advantages over innovative techniques, specifically its full compatibility with the substrate, has hardly been investigated and characterised, from both the experimental and (mainly) the numerical points of view.

\section{Reference vault: methodology and results}

\subsection{Vault structural behaviour}

Masonry structures are in general amongst constructions that are hard to analyse. From the point of view of material parameters to the complexity of the construction, it is usually difficult to define the proper state of a structure. Traditional masonry, as a nonstandardised material, presents heterogeneous properties, and its behaviour should not be considered as linear, especially under tensile stress states. Moreover, past builders and architects showed endless imagination in the manner they created new shapes and construction details, which hinder the analysis of the structural performance of many buildings (Lourenço, 2002; Roca et al., 2010).

Masonry arches and vaults owe their popularity in historical constructions to the remarkable property that they possess - state of compression in which they work. Nevertheless, their stability and safety depend highly on the mechanical properties of the masonry constituents as well as on the geometry. Due to the fact that masonry has a negligible tensile strength, the safety condition of an arch is conditioned by the thrust line lying within the arch itself. If the thrust line becomes tangent at any point of the arch cross section, the formation of plastic hinges will occur. Hinges enhance further arch deformation, by material crushing in the compressed side of the cross section. This changes the structural behaviour of an arch and increases the probability of development of a sufficient number of hinges to transform an arch into a mechanism and to cause its collapse (Heyman, 1982), see Figure 1. 
Figure 1 Line of thrust and failure mechanism of an unstrengthened masonry vault subjected to vertical load applied to (a) middle of the span and (b) a quarter of the arch span (see online version for colours)

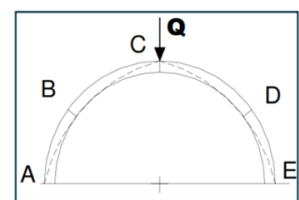

(a)

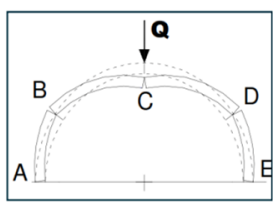

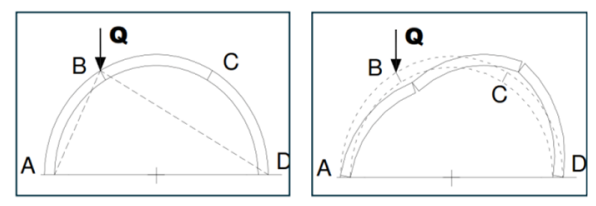

(b)

Source: Valluzzi et al. (2001)

An unstrengthened masonry vault tested in laboratory by Girardello (2013) was here used to develop and validate a numerical model, which later included also a strengthening solution analysis. The reference model is presented in two different modelling strategies, namely macro- and micro-modelling. The vault was tested experimentally and the available results were used to calibrate the two numerical models.

\subsection{Review of experimental work}

The geometry, available material properties and global force-displacements needed for the numerical model calibration were kindly provided by University of Padova (Girardello, 2013). A set of eight vaults was constructed, of which seven included reinforcement of different kind (Steel Reinforced Grout (SRG), SRP, Carbon Fiber Reinforced Polymer (CFRP), Basalt Textile Reinforced Mortar (BTRM) and extrados stiffening diaphragms with SRP and SRG strips). The unreinforced vault was loaded at the quarter span in a monotonic way until failure. The arrangement of vault and load scheme is illustrated in Figure 2. The unstrengthened vault was monitored by a set of Linear Variable Displacement Transducer (LVDT) applied in strategic positions on the structure. The ultimate load of the vault reached $1.38 \mathrm{kN}$, for a keystone displacement equal to $0.39 \mathrm{~mm}$. Collapse happened due to the formation of the four plastic hinges, thus creating the classical failure mechanism.

Figure 2 Unreinforced vault with location of plastic hinges: (a) scheme of the vault and (b) picture of the vault (see online version for colours)

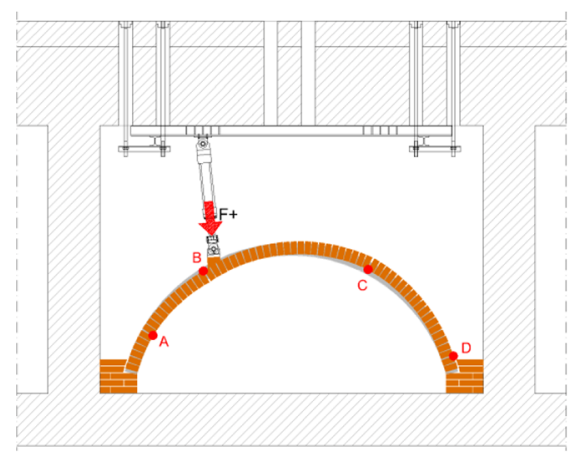

(a)

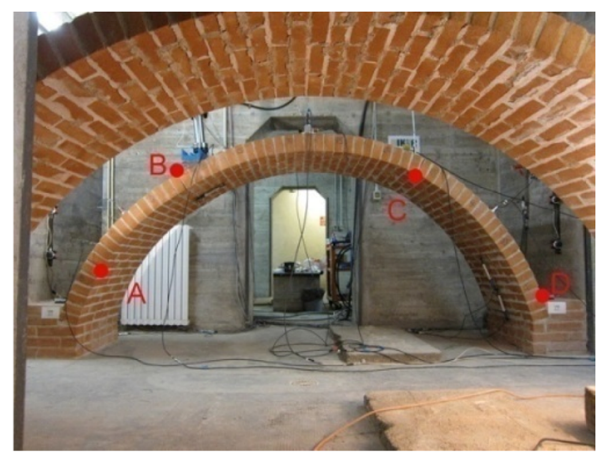

(b)

Source: Girardello (2013) 


\subsection{Numerical modelling}

A large number of numerical researches about masonry arches and vaults has been resorting to micro-modelling to represent the complex behaviour of these structural components. This approach is understandable because characterisation of mortar joints as interfaces is of high importance to credibly reproduce vaults and arches' behaviour. Conversely, macro-modelling is considered to be able to realistically replicate the global behaviour of a structure, rather than some local phenomenon. Nevertheless, macromodelling has an advantage that should be taken into account, which is the higher and quicker feasibility of the model (Lourenço 2002; Roca et al., 2013).

To prepare a realistic reference model used to define the impact of extrados diaphragms, a numerical model was created. A plane-stress two-dimensional model was created in DIANA 9.4 software (DIANA 9.4, 2009). The masonry vault has a 2,980-mm span, 1,140-mm rise, $120-\mathrm{mm}$ voussoir thickness and total width of $770 \mathrm{~mm}$, see also Figure 3. During the analysis, subsequently to the application of the self-weight, a monotonic incremental concentrated load was applied at the quarter span of the vault.

Figure 3 Geometry of the reference model

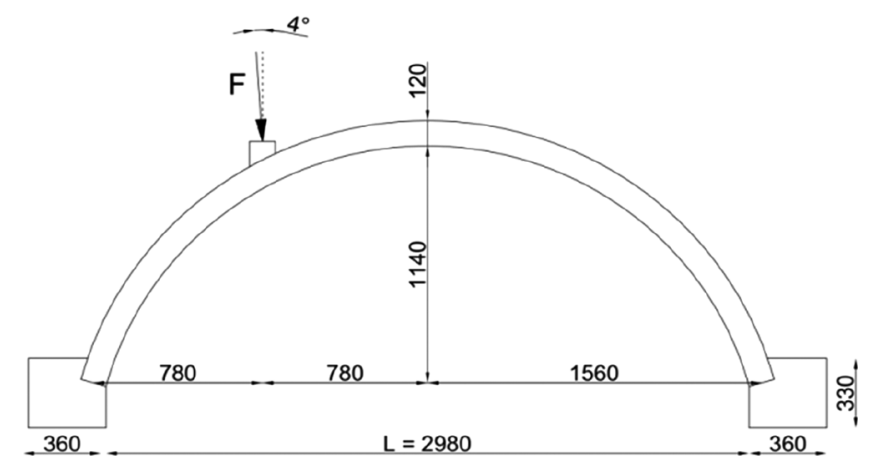

Figure 4 Stress-strain relationships adopted in the analysis: (a) compression and (b) tension

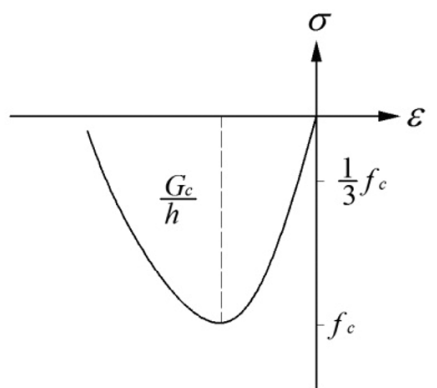

(a)

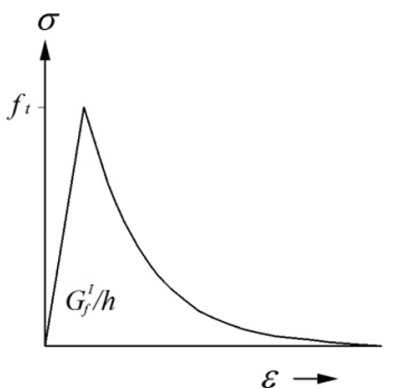

(b) 


\subsubsection{Macro-model approach}

Within a macro-model approach, the material non-linearities of masonry are the governing parameters. The constitutive model, by means of suitable non-linear properties of masonry, should adequately simulate the complex behaviour of the material. Therefore, an important part of the modelling work was connected with defining the material parameters not obtained from the experimental tests of material components.

Masonry was discretised resorting to eight-nodded quadrilateral finite elements, whilst its physical non-linearity is approached by the total strain rotating crack model implemented in DIANA software (DIANA 9.4, 2009), assuming stress-strain relationships parabolic in compression and exponential in tension, see also Figure 4. Total strain crack models have been used to model different historical masonry behaviours with great success (Lourenço et al., 2012; Miccoli et al., 2015).

Figure 5 Mesh used in the micro-model: (a) general view and (b) detail of the modelling

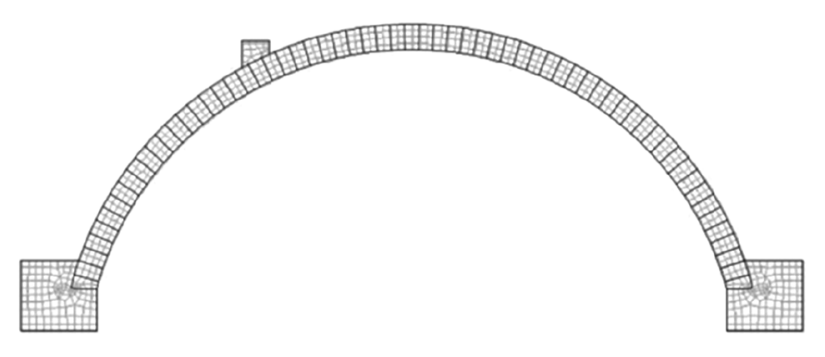

(a)

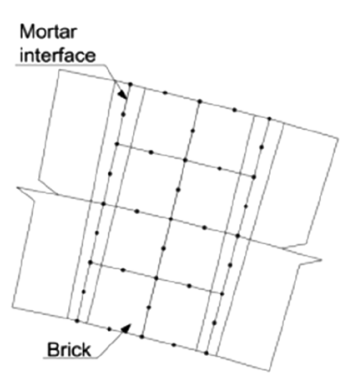

(b)

A preliminary parametric numerical study was carried out to define the suitable parameters for the masonry. The study allowed to define material properties able to create a representative numerical model, in terms of global behaviour and ultimate load. The mechanical properties defined allowed to perform a second parametric study based on reliable data (presented in chapter 4). Most of the properties used to simulate the vault behaviour are provided in (Girardello, 2013). All the elastic and inelastic properties adopted for modelling are listed in Tables 1 and 2, see also DIANA 9.4 (2009) and Ptaszkowska (2013).

Table 1 Elastic properties of masonry and interfaces

\begin{tabular}{lcccc}
\hline Element & $\begin{array}{c}\text { Elastic modulus } \\
\left(\mathrm{N} / \mathrm{mm}^{2}\right)\end{array}$ & $\begin{array}{c}\text { Poisson ratio } \\
(-)\end{array}$ & $\begin{array}{c}\text { Normal stiffness } \\
\left(\mathrm{N} / \mathrm{mm}^{3}\right)\end{array}$ & $\begin{array}{c}\text { Shear stiffness } \\
\left(\mathrm{N} / \mathrm{mm}^{3}\right)\end{array}$ \\
\hline $\begin{array}{l}\text { Masonry MAS1 } \\
\text { (brick) }\end{array}$ & 7,200 & 0.15 & - & - \\
Masonry MAS2 & 1,193 & 0.15 & - & - \\
$\begin{array}{l}\text { Interfaces (INT1 } \\
\text { and INT2) }\end{array}$ & - & - & 21 & 8 \\
\hline
\end{tabular}


Table 2 Inelastic properties of masonry and interfaces

\begin{tabular}{|c|c|c|c|c|c|c|c|c|c|}
\hline & \multicolumn{3}{|c|}{ Tension } & \multicolumn{3}{|c|}{ Shear } & \multicolumn{3}{|c|}{ Compression } \\
\hline & $\underset{\left(N / m m^{2}\right)}{f_{t}}$ & $\begin{array}{c}G_{f}^{1} \\
(\mathrm{~N} / \mathrm{mm})\end{array}$ & $\begin{array}{c}c \\
\left(N / m m^{2}\right)\end{array}$ & $\begin{array}{c}\tan \varphi \\
(-)\end{array}$ & $\begin{array}{c}\tan \phi \\
(-)\end{array}$ & $\begin{array}{c}G_{f}^{11} \\
(\mathrm{~N} / \mathrm{mm})\end{array}$ & $\begin{array}{c}f_{c} \\
\left(\mathrm{~N} / \mathrm{mm}^{2}\right)\end{array}$ & $\begin{array}{c}G_{f c} \\
(\mathrm{~N} / \mathrm{mm})\end{array}$ & $\begin{array}{l}k_{p} \\
(-)\end{array}$ \\
\hline $\begin{array}{l}\text { Masonry } \\
\text { MAS2 }\end{array}$ & 0.04 & 0.02 & - & - & - & - & 5.97 & 9.55 & - \\
\hline $\begin{array}{l}\text { Interface } \\
\text { INT1 }\end{array}$ & 0.07 & 0.02 & 0.17 & 0.43 & 0 & 0.05 & 5.97 & 9.55 & 10 \\
\hline $\begin{array}{l}\text { Interface } \\
\text { INT2 }\end{array}$ & 0.04 & 0.02 & 0.17 & 0.43 & 0 & 0.05 & 5.97 & 9.55 & 10 \\
\hline
\end{tabular}

\subsubsection{Micro-model approach}

For the micro-model approach, the model consists of units and interfaces, which represents the brick units and mortar joints, respectively. For the modelling procedure, units were treated like a continuous elastic material, whilst all the non-linearity of the masonry was concentrated in the interfaces. Therefore, two types of mesh elements were used to describe the structural behaviour. Eight-nodded quadrilateral elements were used for all units, whilst six-nodded zero thickness interface elements were employed for the mortar joints. The adopted mesh is presented in Figure 5.

To define the complex masonry, the crack-shear-crush multi-surface constitutive model was selected for the interfaces, see (DIANA 9.4, 2009) for details. Basically, the model sets a non-linear relation between tractions (i.e. stresses) and relative displacements across a zero thickness interface (Lourenço and Rots, 1997). Parameters for most of the materials were characterised during experimental tests (Girardello, 2013). Values of properties that were not characterised experimentally had to be defined from other experimental and numerical works present in the literature, as discussed in Ptaszkowska (2013). For instance, tensile strength and mode-I fracture energy were estimated during the calibration of the micro-model.

A monotonic incremental load was applied at the quarter-span of the arch, like in the case of the macro-model. To perform the non-linear analysis, the arc-length method and the crack mouth opening displacement technique were employed to surpass instabilities caused by non-linearities associated to the sudden opening of the interfaces.

\subsection{Comparison of results}

To characterise the structural behaviour of the reference vault model, a comparison between experimental and numerical results was conducted. This has been done by defining the ultimate load capacity and the failure mechanism of both models. The two different models, with different degrees of accuracy, gave some interesting outcomes, presented in Table 3. Figure 6 presents the force-displacement curves at two particular points of the model, namely keystone and loading point, for all three models under analysis. The evaluation is made on the resultant displacement for those two points available from experimental results. 
Table 3 Comparison of experimental and numerical results

\begin{tabular}{lccc}
\hline Type of result & $\begin{array}{c}\text { Ultimate load capacity } \\
(\mathrm{kN})\end{array}$ & $\begin{array}{c}\text { Displacement at the } \\
\text { keystone }(\mathrm{mm})\end{array}$ & $\begin{array}{c}\text { Initial stiffness } \\
(\mathrm{kN} / \mathrm{mm})\end{array}$ \\
\hline Experimental & 1.38 & 0.39 & 6.46 \\
Macro-model & 1.41 & 0.52 & 6.03 \\
Micro-model & 1.45 & 0.34 & 5.85 \\
\hline
\end{tabular}

Figure 6 Comparison between experimental and numerical global force-displacement curves: (a) keystone and (b) loading point (see online version for colours)

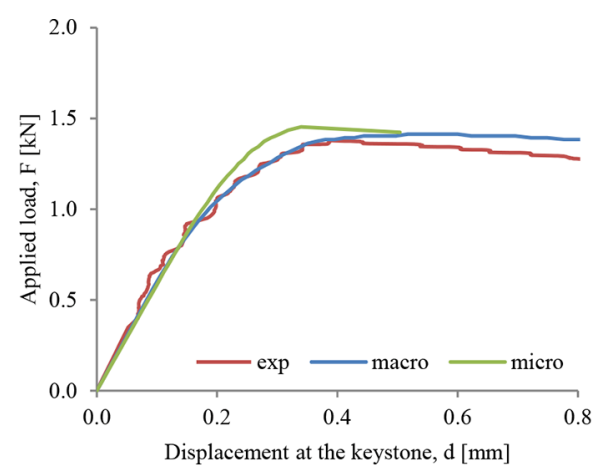

(a)

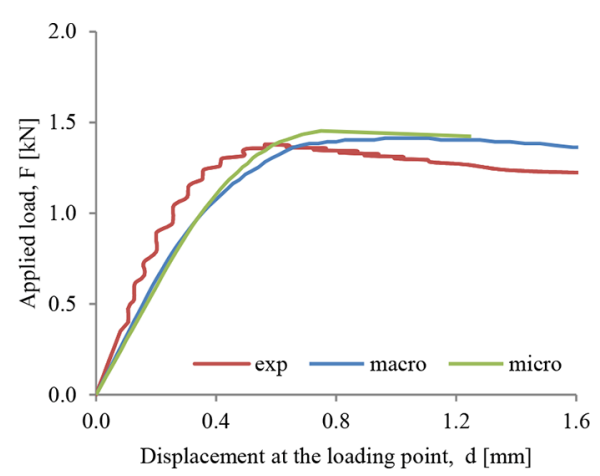

(b)

The numerical response of the macro-model presents a very good correlation with experimental results, especially in terms of initial stiffness and peak load. Figure 6 shows that after the maximum load being reached, a drop in the load-carrying capacity is detected, which can be connected with major damage present in the structure. Additionally, the model and the experimental results show close values of the resultant displacement measured in the keystone and loading point. Four zones of high tensile strains are noticeable in the model, see Figure 7a. Those zones can be correlated with localisation of hinges that developed during experiments. Thus, it can be concluded that the numerical 'collapse mechanism' is due to the occurrence of four plastic hinges.

Figure 7 Principal tensile strain distribution and location of hinges at peak load: (a) macro-model and (b) micro-model (see online version for colours)

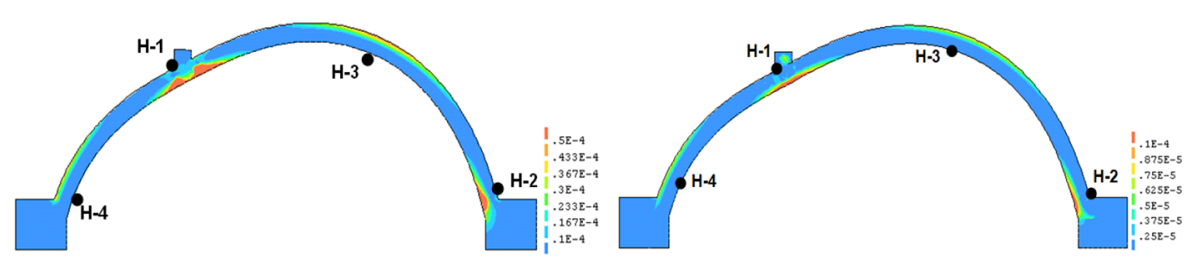

(a)

(b)

The micro-model approach replicates the experimental behaviour in a satisfactory manner. The displacement at peak load is smaller than the real specimen, which signifies that the micro-model is slightly stiffer and also behaves in a brittle manner. Close to the maximum load capacity, the behaviour tends to become non-linear. After reaching the peak load, the model replicates partially the softening branch. The values of the load 
capacity of the model goes above the results from the experiment, whilst at the same time the maximum displacement at peak load is lower than in experiments (keystone section). The initial stiffness of the vault is reasonably close to the experimental value. The model allows to identify the location and the sequence of hinges in the structure (Figure $7 \mathrm{~b}$ ). The identification of hinges is based on a principal tensile strain distribution, which can be related with zones of crack development.

The macro-model approach has the advantage of a simpler pre-processing in terms of model creation, it requires less input data and involves less computational cost. On the other hand, micro-model allows for a more detailed structural behaviour description, which tends to be typically more reliable.

\section{Strengthened vault model}

During the last century, several rehabilitation and strengthening techniques for historical constructions were developed. The introduction of steel ties at the vault springing, for the case of arched structures (Jasieńko et al., 2006), or at the floor level (Tomazevic, 1999) are two good examples of affordable and efficient options, showing also to be reversible interventions, thus respecting the modern principles of conservation (ICOMOS/ISCARSAH Committee, 2003). More recently, the use of FRP-based solutions (Valluzzi et al., 2012) is currently being replaced by the TRM technique (De Felice et al., 2014) due to compatibility problems with the substrate (Valluzzi et al., 2014) and durability concerns (Ghiassi et al., 2014) associated with the former solution.

The idea of strengthening a vault with transversal stiffening masonry diaphragms (also called ribs) applied at the extrados is an idea being rediscovered by engineers thanks to its effectiveness, simplicity in concept and change in the conservation approach towards traditional materials. Extrados stiffening diaphragms can be used in a variety of geometric and material configurations. Traditional spandrel masonry walls reinforced with composite materials have been proposed recently (Girardello, 2013). Some other innovative approaches were also developed, in which the strengthening ribs are made from composite materials or glued timber (Bednarz, 2008; Ferrario, 2013). Depending on the concept, ribs can be understood as a continuous elements located throughout the extrados or as spandrel walls placed on both sides of the extrados of vaults.

\subsection{Macro-model approach}

As in the case of the reference model, the reinforcement based on transversal walls was modelled resorting both to a macro- and a micro-model. The geometry of the stiffening diaphragm was taken from Girardello (2013), see also Figure 8. The stiffening element is located at the extrados of the model in a symmetric manner. The width of the vault is 770 $\mathrm{mm}$ as previously. The stiffening diaphragm is $120-\mathrm{mm}$ thick and is located in the middle of the width of the vault. 
Figure 8 Strengthened vault model: (a) geometry and (b) detailed view of the mesh

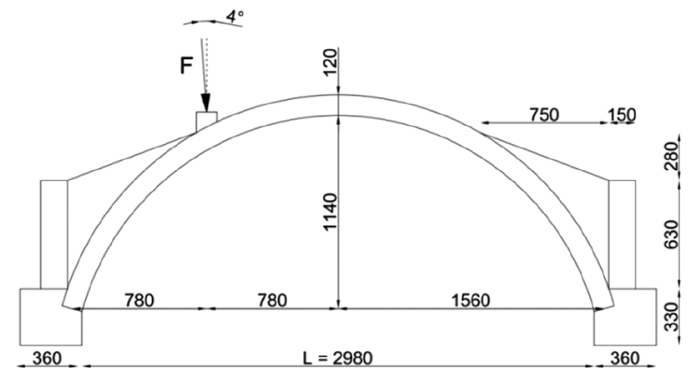

(a)

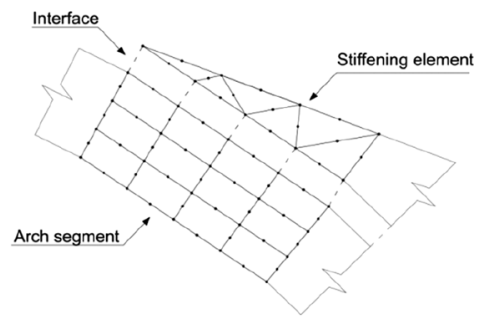

(b)

The macro-model was created as a continuous modelling of the reference vault and of the transversal walls connected to each other with a structural interface. The vault and the diaphragm wall should not be treated as continuously connected, especially in the case of historical constructions, where strengthening is done much later than the vault was erected. To take this aspect into account in the case of macro-modelling approach, the properties of the interface vault-diaphragm had to be taken into consideration to imitate, as closely as possible, the in-situ conditions.

The mesh of the model consists of two types of elements, eight-nodded quadrilateral for the vault and six-nodded triangular for the strengthening part. Six-nodded zero thickness interface elements were adopted to simulate the vault-diaphragm interface, as presented in Figure $8 \mathrm{~b}$.

The constitutive law of the vault-diaphragm interface in the macro-model was taken similar to the micro-model structural interface between units. The properties of masonry were kept like in the case of the plain vault and were applied to both vault and stiffening element. It is here assumed that the diaphragm is made with the same masonry of the vault due to compatibility issues. The material properties used in the numerical model are listed in Tables 1 and 2 (MAS2 and INT2).

Figure 9 presents the load-vertical displacement diagram at the keystone and under the load point. The peak load is increased with regard to the plain vault. The maximum value of the strengthened model is $1.72 \mathrm{kN}$, which means an increase of about $22 \%$. In terms of initial stiffness, the strengthening option doubles it, see also Table 4.

Table 4 Comparison of results for unstrengthened and strengthened macro-models

\begin{tabular}{lccc}
\hline Model & Ultimate load capacity $(\mathrm{kN})$ & $\begin{array}{c}\text { Increase of peak load } \\
(\%)\end{array}$ & $\begin{array}{c}\text { Initial stiffness } \\
(\mathrm{kN} / \mathrm{mm})\end{array}$ \\
\hline $\mathrm{u}$ _arch & 1.41 & - & 6.03 \\
$\mathrm{~s}$ arch & 1.72 & 22 & 11.06 \\
\hline
\end{tabular}


Figure 9 Comparison of results between unstrengthened and strengthened vault models in terms of load-displacement curves (macro-model): (a) keystone and (b) loading point (see online version for colours)

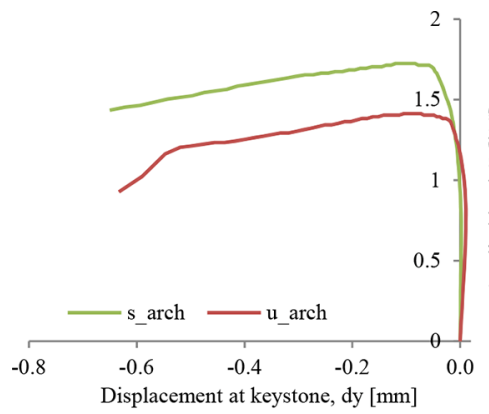

(a)

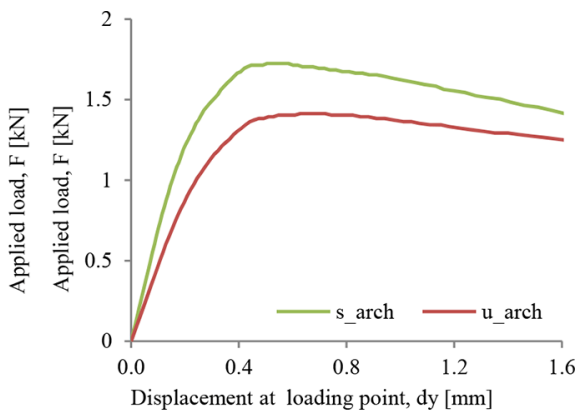

(b)

As in the case of the unstrengthened specimen, failure of the strengthened model seems to be due to the development of a four-hinge mechanism. The sequence of hinge formation is different from the one developed for the plain vault, see also Figure 10a. The hinges form alternately, once on intrados, once on extrados. Although failure is located mostly in the vault itself, also the left stiffening element was affected (Figure 10a). The hinges occurred approximately in positions similar to the unstrengthened vault, but now cracks appear also in the diaphragms.

Figure 10 Principal tensile strain distribution and location of hinges at peak load: (a) macro-model and (b) micro-model (see online version for colours)

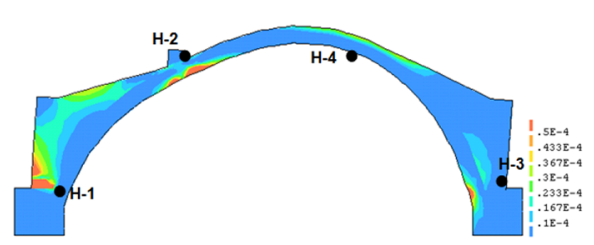

(a)

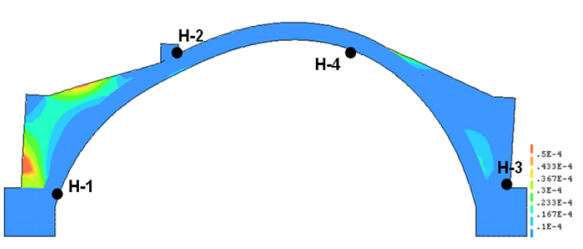

(b)

\subsection{Micro-model approach}

For the micro-modelling of the strengthened vault, two types of interfaces were employed, one between unit-unit, and another between unit-diaphragm. For a more realistic representation, a set of different properties for both interfaces were used, since it is obvious that a newly laid mortar cannot have the same properties as the old one. The geometry of the strengthened micro-model is the same as presented in Figure 8. In order to replicate the reinforced vault, different materials were used for each component of the model, see also Figure 11. 
Figure 11 Geometry of the strengthened arch with indication of all material types

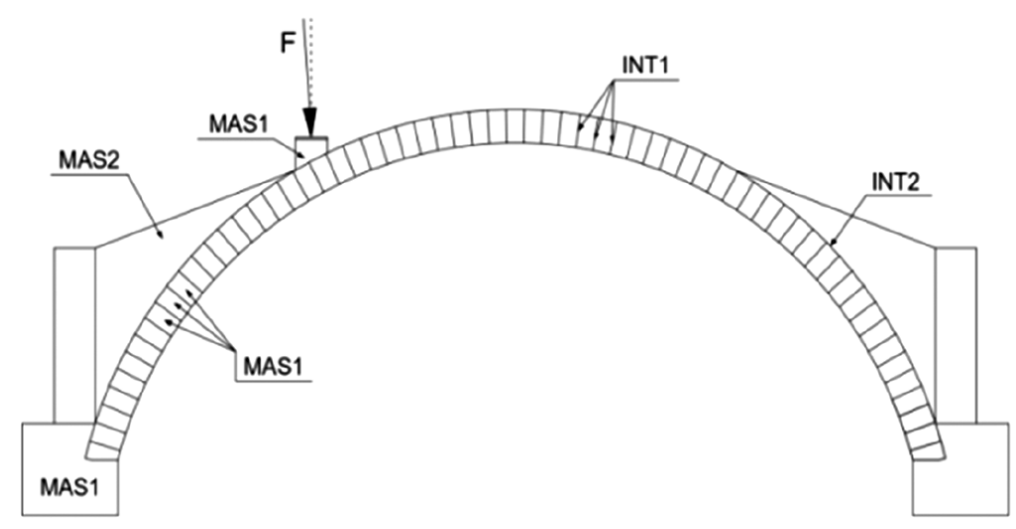

The mesh adopted consists of eight-nodded quadrilateral elements for the units, sixnodded triangular for the stiffening diaphragm and six-nodded structural interfaces, see Figure 12. Like before, the model was analysed in terms of structural response to a monotonic incremental load. Material properties are listed in Tables 1 and 2.

Figure 12 Mesh used in the micro-model: (a) general view and (b) detail of the unit-diaphragm connection

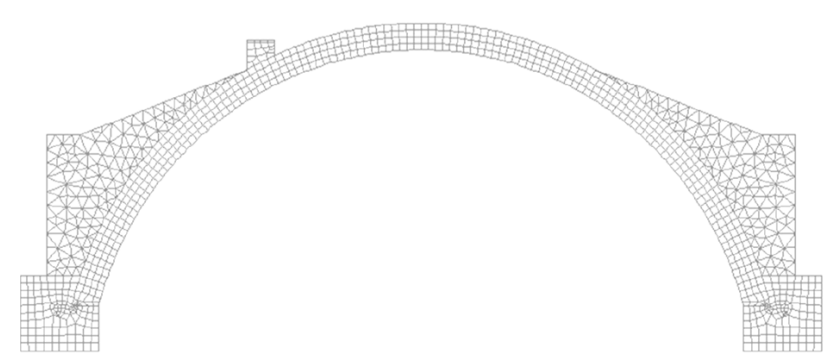

(a)

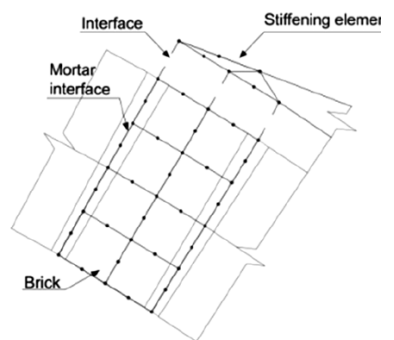

(b)

The load-displacement curve of the strengthened micro-model approach is represented in Figure 13. The displacement in the vertical direction of the keystone is very low, around $0.01 \mathrm{~mm}$. This might be linked with the fact that the unstrengthened model did not replicate the post-peak behaviour in the most suitable way. The keystone first behaves like in the plain vault, going downwards, but with increasing load the deformation is greater and affects the displacement of the keystone, which starts to move upwards (Figure 13a). The displacement of the loading point moved progressively from an elastic to a hardening behaviour, ending with a slightly softening behaviour, typical of kinematics (Figure 13b). 
Figure 13 Comparison of results between unstrengthened and strengthened vault models in terms of load-displacement curve (micro-model): (a) keystone and (b) loading point (see online version for colours)

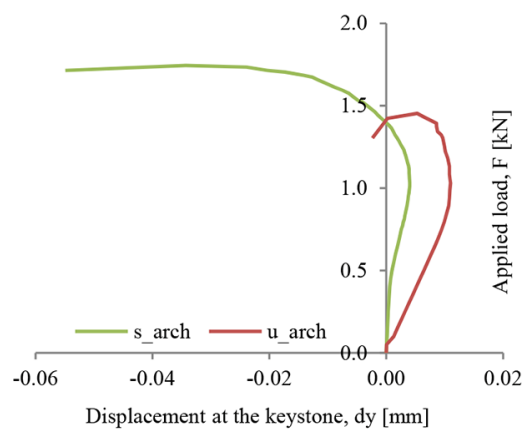

(a)

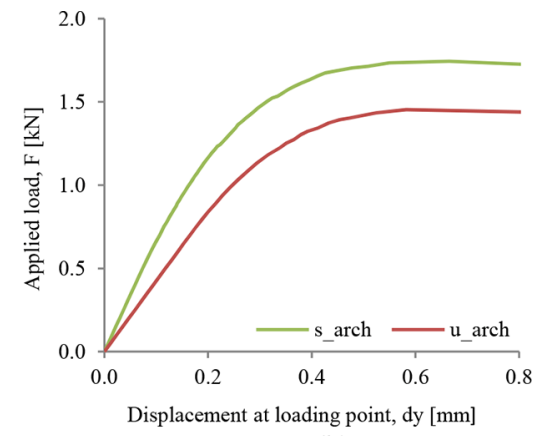

(b)

Once again, the presence of a masonry diaphragm alters the structural response of the vault in terms of initial stiffness and ultimate capacity. Initial stiffness in the vertical direction increases highly, almost doubled its value, whilst the maximum value observed an increase of about $20 \%$. All the comparable parameters are listed in Table 5. Finally, the concentration of high principal tensile strains around four locations, see Figure 10b, seems to indicate the formation of a four hinge mechanism, involving also the masonry diaphragms, but not so obvious as for the macro-model one.

Table 5 Comparison of results for unstrengthened and strengthened micro-models

\begin{tabular}{lccc}
\hline Type of arch & $\begin{array}{c}\text { Ultimate load capacity } \\
(\mathrm{kN})\end{array}$ & $\begin{array}{c}\text { Increase of peak load } \\
(\%)\end{array}$ & $\begin{array}{c}\text { Initial stiffness } \\
(\mathrm{kN} / \mathrm{mm})\end{array}$ \\
\hline $\mathrm{u}$ arch & 1.45 & - & 5.85 \\
s_arch & 1.74 & 20 & 11.54 \\
\hline
\end{tabular}

\section{Parametric study}

To fully exploit the potential of the calibrated numerical model, a parametric study was established to understand the response of the strengthened vaults to variations of potential key material and geometric parameters of the stiffening diaphragm. Three variations were then considered, but without changes in the meshes. Only the macro-model will be used for the parametric study, due to its higher simplicity and smaller computational costs of analysis. Additionally, the macro-model performed better in terms of post-peak behaviour. Three types of parametric analysis were considered in the macro-model, as follows:

1 increase of the extrados stiffening diaphragm thickness from 12 to $24 \mathrm{~cm}$ (s_arch_2)

2 increase of the diaphragm masonry properties, doubling the Young's modulus and compressive and tensile strengths (s_arch_3, see Table 6). 
Table 6 Values of properties of the original and changed (s_arch_3) model

\begin{tabular}{lccccc}
\hline $\begin{array}{l}\text { Properties of } \\
\text { the masonry } \\
\begin{array}{l}\text { of the } \\
\text { diaphragm }\end{array}\end{array}$ & $\begin{array}{c}\text { Elastic } \\
\text { modulus }\end{array}$ & \multicolumn{2}{c}{ Tension } & \multicolumn{2}{c}{ Compression } \\
\cline { 2 - 6 } & $E\left(N / \mathrm{mm}^{2}\right)$ & $f_{t}\left(\mathrm{~N} / \mathrm{mm}^{2}\right)$ & $G_{f}^{l}\left(\mathrm{~N} / \mathrm{mm}^{2}\right)$ & $f_{c}\left(\mathrm{~N} / \mathrm{mm}^{2}\right)$ & $G_{f c}\left(\mathrm{~N} / \mathrm{mm}^{2}\right)$ \\
\hline $\begin{array}{l}\text { Original } \\
\text { values }\end{array}$ & 1,193 & 0.04 & 0.02 & 5.97 & 9.55 \\
\begin{tabular}{l} 
New values \\
\hline
\end{tabular} & 2,400 & 0.08 & 0.02 & 12 & 9.55 \\
\hline
\end{tabular}

3 increase of the vault-diaphragm interface properties, doubling the tensile strength, increasing cohesion and normal and shear stiffness (s_arch_4, see Table 7).

Table 7 Values of properties of the original and changed (s_arch_4) model

\begin{tabular}{lcccc}
\hline $\begin{array}{l}\text { Properties' } \\
\text { values of the } \\
\text { interface }\end{array}$ & $\begin{array}{c}\text { Normal stiffness } \\
k_{n}\left(\mathrm{~N} / \mathrm{mm}^{3}\right)\end{array}$ & $\begin{array}{c}\text { Shear stiffness } \\
k_{s}\left(\mathrm{~N} / \mathrm{mm}^{3}\right)\end{array}$ & $\begin{array}{c}\text { Tensile strength } \\
f_{t}\left(\mathrm{~N} / \mathrm{mm}^{2}\right)\end{array}$ & $\begin{array}{c}\text { Cohesion } \\
c\left(\mathrm{~N} / \mathrm{mm}^{2}\right)\end{array}$ \\
\hline Original values & 21 & 8.4 & 0.072 & 0.173 \\
New values & 210 & 84 & 0.14 & 0.25 \\
\hline
\end{tabular}

Each change causes a variation in terms of the load-carrying capacity that the vault can sustain. The comparison of results for the three parametric variations is illustrated in Figure 14 and listed in Table 8. The largest influence is due to the doubling of the diaphragm thickness (s_arch_2), allowing to reach a peak load value of $1.95 \mathrm{kN}$ (about $13 \%$ increase). Also, this reinforcement showed the highest initial stiffness, as expected, with an increment of about $27 \%$.

Figure 14 Comparison of results in terms of load-displacement curve for: (a) keystone and (b) loading point (see online version for colours)

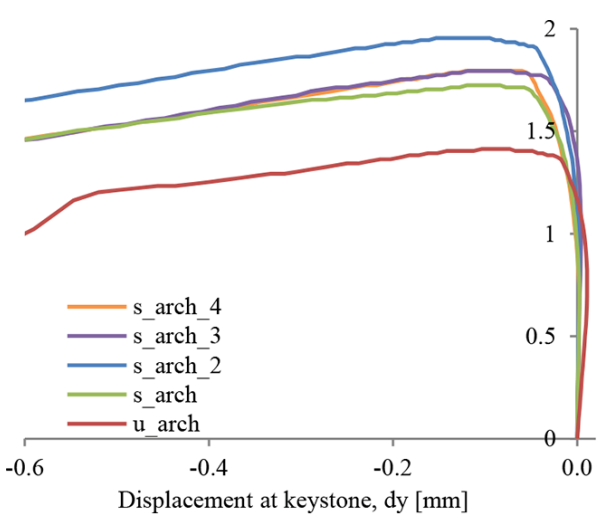

(a)

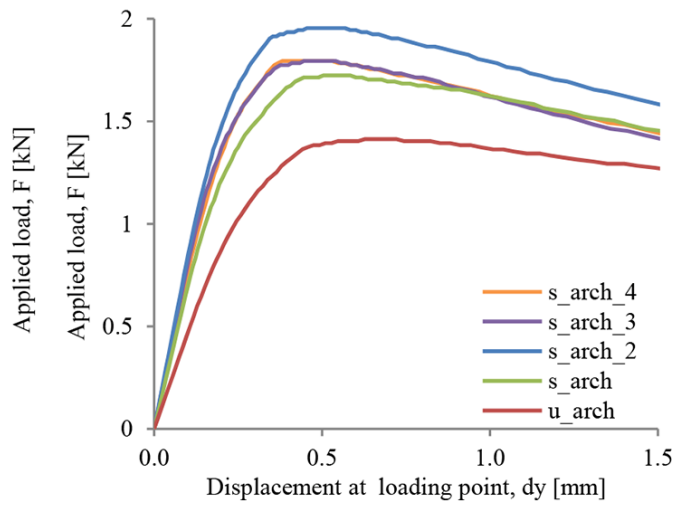

(b) 
Table 8 Comparison of results for all macro-models studied

\begin{tabular}{lccc}
\hline Model & $\begin{array}{c}\text { Ultimate load capacity } \\
(\mathrm{kN})\end{array}$ & $\begin{array}{c}\text { Increase of peak load } \\
(\%)\end{array}$ & $\begin{array}{c}\text { Initial stiffness } \\
(\mathrm{kN} / \mathrm{mm})\end{array}$ \\
\hline u_arch & 1.41 & - & 6.03 \\
s_arch & 1.72 & 22 & 11.06 \\
s_arch_2 & 1.95 & 38 & 14.06 \\
s_arch_3 & 1.79 & 27 & 13.02 \\
s_arch_4 & 1.79 & 27 & 12.41 \\
\hline
\end{tabular}

The use of a better masonry quality (s_arch_3) in the diaphragm did not bring important changes in the load-bearing capacity. An increase of only 4\% does not seem worth further consideration. The last modification (s_arch_4), regarding the improvement of the properties of the mortar connecting the diaphragm to the vault, led to a small increase of both stiffness and strength, quite similar to the case of a better masonry.

\section{Discussion}

\subsection{Strengthened models}

Two different numerical modelling strategies aimed at understanding the effect of stiffening diaphragms on the behaviour of masonry vaults and to clarify the influence of the degree of detail introduced have been developed. The extrados diaphragm clearly modified the static behaviour of the vault, basically doubling the initial stiffness and increasing the maximum load by $20 \%$, however the collapse mechanism observed was connected with the development of four plastic hinges, as in the case of the plain vault.

The macro-model was able to replicate the post-peak behaviour of the strengthened arch further than the micro-model did. Additionally, it required less computational time and input data. Conversely, the micro-model required higher computational costs and its structural response showed to be more brittle, which might be seen as a structural response closer to experiments, more detailed at the local level.

The results in terms of ultimate load capacity of both reinforced models were very similar (1.72 and $1.74 \mathrm{kN}$, for macro- and micro-, respectively). The same was observed for the initial stiffness, where both models were working in a range around $11,000 \mathrm{~N} / \mathrm{mm}$. The macro-model showed a higher displacement capacity. As the results in terms of strength and initial stiffness are similar for macro- and micro-model, it can be concluded that the strengthening technique is efficient and worth considering whilst thinking about future reinforcement options applied to masonry vaults. However, it should be used in cases that do not require a high increase in strength or possibly in combination with other strengthening techniques.

\subsection{Parametric study}

The modifications applied to the original strengthened vault did not alter significantly the strength nor its initial stiffness. However, amongst the three proposed changes, the one worth considering is the use of a thicker stiffening element. It is not clear whether the 
simultaneous application of all proposed changes could significantly increase the carrying capacity of the original strengthened vault.

\section{Conclusion}

This paper was devoted to the numerical study of an uncommon strengthening solution for arches and vaults, based on the use of fully compatible transversal stiffening masonry diaphragms. From the numerical work carried out, the following main conclusions can be drawn:

- For the particular structure analysed, micro- and macro-modelling strategies are applicable since both techniques were able to reach approximate values and to replicate the observed experimental behaviour of the unstrengthened specimen.

- The use of extrados stiffening diaphragms seems a suitable method for improvement of the structural response of masonry arches and vaults, mainly in terms of initial stiffness. However, if the aim of strengthening is a significant improvement in load capacity, then the technique should be combined with another one or not considered.

- The parametric study performed on the macro-model showed a variety of results. Material changes of the masonry of the stiffening element did not alter the response of the structure much, however the geometric variation of the diaphragm thickness revealed an important impact on the capacity of the vault.

\section{References}

Bednarz, L. (2008) Historic Curved Brick Structures Undergoing Repair and Strengthening (in Polish), PhD Thesis, Politechnika Wrocławska, Wrocław, Poland.

Carocci, C. (2001) 'Guidelines for the safety and preservation of historical centres in seismic areas', Proc. 3rd Int. Sem. Histor. Construct., University of Minho, Guimaraes, pp.145-165.

De Felice, G., De Santis, S., Garmendia, L., Ghiassi, B., Larrinaga, P., Lourenço, P.B., Oliveira, D.V. and Papanicolaou, C.G. (2014) 'Mortar-based systems for externally bonded strengthening of masonry', Materials and Structures, Vol. 47, No. 12, pp.2021-2037.

DIANA 9.4 (2009) DIsplacement method ANAlyser User's Manual, release 9.4, TNO, Netherlands.

Ferrario, L. (2013) Masonry Single-Leaf Vaults: From the Seismic Vulnerability Assessment to the Proposal of an Innovative Retrofitting Approach, PhD Thesis, University of Brescia, Brescia, Italy.

Garmendia, L., San-José, J.T., García, D. and Larrinaga, P. (2011) 'Rehabilitation of masonry arches with compatible advanced composite materials', Construction and Building Materials, Vol. 25, No. 12, pp.4374-4385.

Ghiassi, B., Oliveira, D.V. and Lourenço, P.B. (2014) 'Hygrothermal durability of bond in FRPstrengthened masonry', Materials and Structures, Vol. 47, No. 12, pp.2039-2050.

Girardello, P. (2013) Reinforcement of Masonry Vaults with Innovative Composite Materials (in Italian), PhD Thesis, University of Brescia, Brescia, Italy.

Heyman, J. (1982) The Masonry Arch, Chichester, UK: Ellis Horwood Seriesin Engineering Science. 
ICOMOS/ISCARSAH Committee. (2003) ICOMOS Charter - Principles for the Analysis, Conservation and Structural Restoration of Architectural Heritage, ICOMOS 14th General Assembly, Victoria Falls, Zimbabwe.

Jasieńko, J., Lodygowski, T. and Rapp, P. (2006) Repair, Maintenance and Strengthening of Selected Historic Brick Structures (in Polish), Dolnosląskie Wydawnictwo Edukacyjne, Wroclaw.

Lourenço, P.B. (2002) 'Computations on historic masonry structures', Progress in Structural Engineering and Materials, Vol. 4, pp.301-319.

Lourenço, P.B. and Rots J.G. (1997) 'A multi-surface interface model for the analysis of masonry structures', Journal of Engineering Mechanics, ASCE, Vol. 123, No. 7, pp.660-668.

Lourenço, P.B., Trujillo, A., Mendes, N. and Ramos, L.F. (2012) 'Seismic performance of the St. George of the Latins church: Lessons learned from studying masonry ruins', Engineering Structures, Vol. 40, pp.501-518.

Miccoli, L., Oliveira, D.V., Silva, R.A., Müller, U. and Schueremans, L. (2015) 'Static behaviour of rammed earth: experimental testing and finite element modelling', Materials and Structures, Vol. 48, No. 10, pp.3443-3456.

Ministero per i beni e le attività culturali. (2010) Guidelines for the assessment and mitigation of seismic risk of cultural heritage in line with the new technical standards for construction/Linee guida per la valutazione e riduzione del rischio sismico del patrimonio culturale allineate alle nuove norme tecniche per le costruzioni (Italian Standard, in Italian).

Ochsendorf, J. (2002) The Collapse of Masonry Structures, PhD Thesis, University of Cambridge, Cambridge, UK.

Oliveira, D.V., Basilio, I., and Lourenço, P.B. (2010) 'Experimental behavior of FRP strengthened masonry arches', Journal of Composites for Construction, Vol. 14, No. 3, pp.312-322.

Ptaszkowska, J. (2013) Numerical Modelling of Masonry Vaults Strengthened with Transversal Diaphragms, MSc Thesis, University of Minho, Portugal.

Roca, P., Cervera, M., Gariup, G. and Pela, L. (2010) 'Structural analysis of masonry historical constructions. Classical and advanced approaches,' Archives of Computational Methods in Engineering, Vol. 17, pp.299-325.

Roca, P., Cervera, M., Pela, L., Clemente, R. and Chiumenti, M. (2013) 'Continuum FE models for the analysis of Mallorca Cathedral', Engineering Structures, Vol. 46, pp.653-670.

Tomazevic, M. (1999) Earthquake-Resistant Design of Masonry Buildings, Imperial College Press, London.

Valluzzi, M.R., Modena, C. and de Felice, G. (2014) 'Current practice and open issues in strengthening historical buildings with composites', Materials and Structures, Vol. 47, No. 12, pp.1971-1985.

Valluzzi, M.R., Oliveira, D.V., Caratelli, A., Castori, G., Corradi, M., de Felice, G., Garbin, E., Garcia, D., Garmendia, L., Grande, E., Ianniruberto, U., Kwiecień, A., Leone, M., Lignola, G.P., Lourenço, P.B., Malena, M., Micelli, F., Panizza, M., Papanicolaou, C.G., Prota, A., Sacco, E., Triantafillou, T.C., Viskovic, A., Zając, B. and Zuccarino, G. (2012) 'Round Robin test for composite-to-brick shear bond characterization', Materials and Structures, Vol. 45, No. 12, pp.1761-1791, .

Valluzzi, M.R., Valdemarca, M. and Modena, C. (2001) 'Experimental analysis and modeling of brick masonry vaults strengthened by FRP laminates', Journal of Composites for Construction, Vol. 5, No. 3, pp.163-169. 